\title{
Influence of Preoperative Astigmatism Type and Magnitude on the Effectiveness of SMILE Correction
}

\author{
Ricardo Pérez-Izquierdo, MD; Manuel Rodríguez-Vallejo, PhD; Alicia Matamoros, OD; \\ Javier Martínez, OD; Nuria Garzón, PhD; Francisco Poyales, MD; Joaquín Fernández, MD, PhD
}

\section{ABSTRACT}

PURPOSE: To assess the effectiveness of small incision lenticule extraction (SMILE) as a function of the astigmatism level and type.

METHODS: A total of 102 right eyes were included in this study. Refractive astigmatism and corneal astigmatism measured with Scheimpflug technology were retrieved from the preoperative visit and the 3 -month follow-up visit. Patients were split into three groups according to the preoperative refractive astigmatism $(0.50,0.75$ to 1.25 , and 1.50 diopters [D] or greaterl and the effectiveness among each group was evaluated according to the with-the-rule (WTR), against-therule (ATR), and oblique classifications. The standard Alpins method was used for the analysis.
RESULTS: Resultant astigmatism was not associated with its preoperative classification when the total sample was considered, but a significant association emerged between the presence of resultant astigmatism and its preoperative classification in the $1.50 \mathrm{D}$ or greater group. The magnitude of error was significantly lower in the WTR (median: -0.30 D) than in the oblique and ATR astigmatism groups, resulting in a coefficient of adjustment of 1.13 for WTR astigmatism of $1.50 \mathrm{D}$ or greater but not for the other types.

CONCLUSIONS: Astigmatism correction with SMILE is predictable for astigmatism lower than $1.50 \mathrm{D}$ without the need to apply a correction. However, higher undercorrection is present in WTR astigmatism of 1.50 D or greater.

\section{[J Refract Surg. 201X;X(X):XX-XX.]}

$\mathbf{S}$ ince the advent of the SMILE surgical approach, surgeon experience, innovations in laser technologies, and nomogram adjustments have led to improvements in visual and refractive outcomes. ${ }^{1-3}$ Several studies have assessed SMILE's performance,,$^{1,2,4-6}$ concluding that it yields high refractive predictability, safety, and patient satisfaction, which is comparable to that provided by femtosecond laserassisted LASIK..$^{7-9}$ However, there is still some controversy when it comes to treating astigmatism with SMILE. ${ }^{10}$

Some patients who have SMILE may have a resultant refractive error, induced astigmatism, or regression. ${ }^{10,11}$ If their resultant refractive error is significant enough, these patients may seek further refractive correction or enhancement. Re-treatment rates after SMILE have not been extensively reported, but Re- instein et al. ${ }^{12}$ reported a $4 \%$ enhancement rate after low myopic treatment (spherical equivalent [SE] up to -3.50 diopters [D] and cylinder up to 1.50 D). Fernández et al. ${ }^{6}$ found significant undercorrection cases within a high myopia group ( -5.00 to $-7.00 \mathrm{D})$, whereas the low and medium myopia groups remained close to emmetropia. Recchioni et al. ${ }^{13}$ found a non-negligible postoperative SE in $18 \%$ of their patients at the 3-month follow-up visit (preoperative SE: -10.88 to $-1.25 \mathrm{D}$, mean: $-5.61 \mathrm{D})$.

Several studies have determined the preoperative factors that could affect the enhancement after SMILE: age, ${ }^{14,15}$ manifest refractive $\mathrm{SE},{ }^{14-16}$ sphere, ${ }^{15}$ cylinder, ${ }^{3}$ and cap thickness. ${ }^{17}$ Recently, it has been also suggested that the effectiveness might depend on the astigmatism type, ${ }^{18-20}$ but as far as we know there is no peer reviewed publication to date that evaluates the

From IOA Madrid Innova Ocular, Madrid, Spain (RP-I, AM, NG, FP); the Department of Ophthalmology (Qvision), Vithas Virgen del Mar Hospital, Almería, Spain (MR-V, JM, JF); and the Department of Ophthalmology, Torrecárdenas Hospital Complex, Almería, Spain (JF).

Submitted: April 18, 2018; Accepted: November 26, 2018

The authors have no financial or proprietary interest in the materials presented herein.

Correspondence: Nuria Garzón, PhD, IOA Madrid Innova Ocular, c/ Galileo 104, Madrid 28003, Spain. E-mail: ngarzon@ioamadrid.com 
influence of astigmatism classification and degree in the effectiveness of the procedure. The main aim of this study was to evaluate the effectiveness of SMILE according to the astigmatism level and type.

\section{PATIENTS AND METHODS}

This was a retrospective observational study that included all SMILE surgeries performed between January and December 2016 at our eye clinic (IOA Madrid Innova Ocular, Spain) by two experienced SMILE surgeonsAQ1. Informed consent and permission to use their data for analysis and publication were obtained from each patient prior to surgery as part of our routine preoperative protocol. The study was conducted in accordance with the tenets of the Declaration of Helsinki.

All patients referred to our facilities for corneal refractive surgery underwent a preoperative examination that included manifest refraction, tonometry, pupillometry (OPD III Scan; NIDEK Co. Ltd., Gamagori, Japan), Pentacam HR corneal tomography (Oculus Optikgeräte $\mathrm{GmbH}$, Wetzlar, Germany), biomicroscopy, and fundus examination. The postoperative manifest refraction and Pentacam HR corneal tomography were conducted during the 3-month follow-up visit.

\section{SURGICAL PROCEDURE}

A VisuMax $500-\mathrm{kHz}$ femtosecond laser (Carl Zeiss Meditec, Jena, Germany) was used for the SMILE procedure. Surgery was performed bilaterally and under topical anesthesia by instilling two drops of $0.4 \%$ oxybuprocaine 5 minutes and 1 minute before surgery initiation.

As part of the preoperative patient preparation process, two marks were made at the limbus on the horizontal axis $\left(0^{\circ}\right.$ to $\left.180^{\circ}\right)$ at the 9 - and 3-o'clock positions, using a fine-tipped gentian-violet marker (Devon Skin Marker, Fine Tip 151AQ2) under slit-lamp observation. The marks' positioning was confirmed by taking a picture of the patient, who was standing $2.5 \mathrm{~m}$ from a camera that was held in place with a clamping system that ensured a correct horizontal position. The optical zooming functionality allowed us to simultaneously photograph both eyes. The image was then exported to a computer and analyzed with Goniotrans (Software Goniotrans, SpainAQ2), a free software that allows precise angle measurements. This way we were able to measure on the photograph the angle between the line going through both limbus marks and the horizontal line that transects the corneal reflex. This gives the exact position of the marks and their angular difference with respect to the "real" $0^{\circ}$ to $180^{\circ}$ line.

Next, with the patient lying down, corneal marks were made along this real $0^{\circ}$ to $180^{\circ}$ line using a
Mendez ring, taking as reference the photograph that showed the precise position of the marks that had been previously made in the limbus. These corneal marks need to be made $2 \mathrm{~mm}$ from the limbus, so that they can still be observed under the microscope once docking has been performed.

Due to the cyclotorsion that occurs when patients are lying down, the real $0^{\circ}$ to $180^{\circ}$ line is not usually parallel to the reticle seen in the microscope's right viewfinder. In that case, the sucking cone should be manually rotated to match the corneal marks (the ones along the $0^{\circ}$ to $180^{\circ}$ line) with the reticle.

Once appropriate centration had been achieved, suction was applied to the contact glass. As for the laser settings, we used a laser cut energy index of 25 (corresponding to approximately $125 \mathrm{~mJ}$ ) and a spot spacing of $4.5 \mu \mathrm{m}$. Lenticule diameter (optical zone) ranged between 6.5 and $7.2 \mathrm{~mm}$, whereas cap diameter was 7.3 $\mathrm{mm}$ and cap thickness was $120 \mu \mathrm{m}$. A side-cut incision (mean: $2.5 \mathrm{~mm}$; range: 2 to $5 \mathrm{~mm}$ ) was created at $135^{\circ}$.

Immediately after surgery, the patient received 0.5\% moxifloxacin (Vigamox; Alcon Laboratories, Inc., Fort Worth, TX) and 1\% prednisolone acetate (Pred Forte; Allergan, Inc., Irvine, CA) eye drops. In addition, dexamethasone and ofloxacin (Exocin; Allergan, Inc.) were administered four times daily for 3 days and dexamethasone eye drops were used three times daily from the fourth day to the end of the second week and two times daily during the third week postoperatively.

\section{STATISTICAL ANALYSIS}

Non-parametric tests and median with interquartile range (IQR) for central tendency and dispersion were used due to the data being non-normally distributed, as emerged from the Kolmogorov-Smirnov test. A positive conversion of the cylinder to the corneal plane was performed before conducting the vector analysis. Astigmatism was classified according to the cylinder's axis orientation using positive notation (with-the-rule [WTR]: $90^{\circ} \pm 29^{\circ}$; against-the-rule [ATR]: either $180^{\circ}$ to $151^{\circ}$ or $0^{\circ}$ to $29^{\circ}$; and oblique: $30^{\circ}$ to $60^{\circ}$ or $120^{\circ}$ to $150^{\circ}$ ) because this classification matches the standard plots. ${ }^{21}$ Three groups were also created according to the 33rd percentile astigmatism magnitude (0.50, 0.75 to $1.25 \mathrm{D}$, and $1.50 \mathrm{D}$ or greater). The chi-square test for proportions was used to detect any statistically significant association between nominal variables; however, for the cases in which all expected cell frequencies were not greater than 5, the Fisher exact test was used instead. The Kruskal-Wallis test was selected to evaluate the differences between WTR, ATR, and oblique for each level of astigmatism. 


\begin{tabular}{|c|c|c|c|c|}
\hline \multicolumn{5}{|c|}{$\begin{array}{c}\text { TABLE } 1 \\
\text { Preoperative Refractive Astigmatism at the Corneal Plane (Magnitude and Orientation) }\end{array}$} \\
\hline Astigmatism & WTR & Oblique & ATR & $P^{a} A Q 3$ \\
\hline \multicolumn{5}{|l|}{$0.50 \mathrm{D}$} \\
\hline No. & $19(18.6 \%)$ & $5(4.9 \%)$ & $10(9.8 \%)$ & - \\
\hline Cylinder (D), median (IQR) & $0.45(0.02)$ & $0.45(0.03)$ & $0.45(0.03)$ & chi-square $(2)=0.71, P=.70$ \\
\hline Sphere (D), median (IQR) & $-4.04(1.58)$ & $-4.04(2.40)$ & $-3.92(2.24)$ & chi-square $(2)=0.71, P=.70$ \\
\hline \multicolumn{5}{|l|}{0.75 to $1.25 \mathrm{D}$} \\
\hline No. & $21(20.6 \%)$ & $6(5.9 \%)$ & $9(8.8 \%)$ & - \\
\hline Cylinder (D), median (IQR) & $0.91(0.24)$ & $0.83(0.26)$ & $0.86(0.21)$ & chi-square $(2)=0.29, P=.86$ \\
\hline Sphere (D), median (IQR) & $-3.35(1.84)$ & $-2.42(2.06)$ & $-3.90(2.83)$ & chi-square(2) $=5.16, P=.08$ \\
\hline \multicolumn{5}{|l|}{$\geqslant 1.50 \mathrm{D}$} \\
\hline No. & $14(13.7 \%)$ & $4(3.9 \%)$ & $14(13.7 \%)$ & - \\
\hline Cylinder (D), median (IQR) & $1.99(1.48)$ & $1.83(1.21)$ & $1.83(1.37)$ & chi-square(2) $=0.76, P=.68$ \\
\hline Sphere (D), median (IQR) & $-2.19(3.25)$ & $-2.06(1.66)$ & $-2.89(3.83)$ & chi-square $(2)=1.11, P=.57$ \\
\hline
\end{tabular}

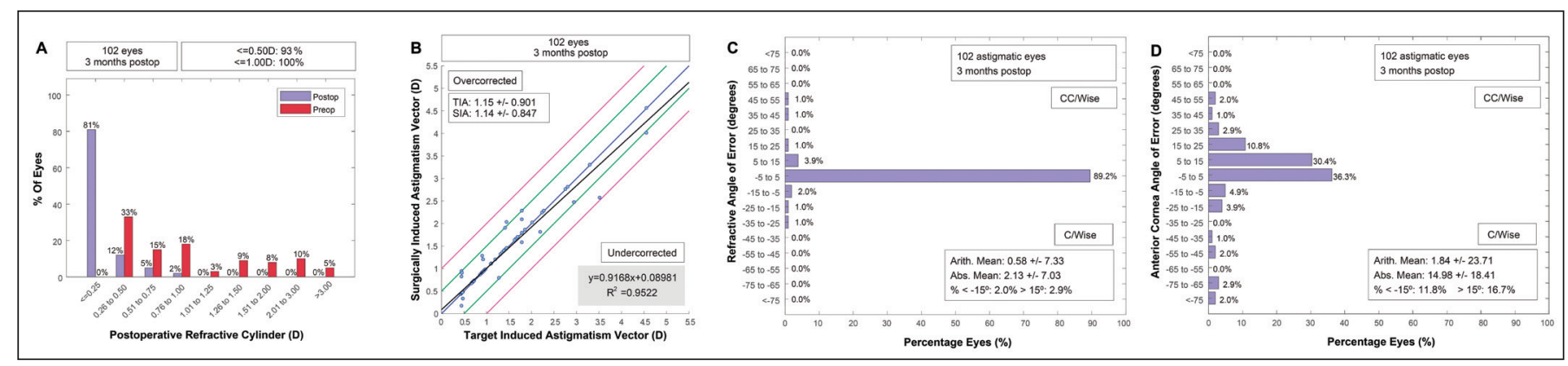

Figure 1. (A) Histogram of preoperative and postoperative astigmatism, (B) linear regression for the prediction of surgically induced astigmatism vector (SIA) by means of the target induced astigmatism vector (TIA), (C) angle of error histogram on which the negative values indicate that the refractive SIA is clockwise to the TIA and positive values indicate that the SIA is counterclockwise to the TIA, and (D) angle of error histogram for the anterior cornea.

The standards for reporting astigmatism values and outcomes ${ }^{21}$ were followed, both in terms of the terminology used in the current study and for astigmatism analysis by the Alpins method. ${ }^{22}$ All figures and vector computations were performed using the Refractive Analysis toolbox ${ }^{23}$ for MATLAB (R2009; MathWorks, Natick, MA). Data analysis was carried out using the IBM SPSS for Windows statistical software (version 20.0; SPSS, Inc., Chicago, IL); for all statistical tests that we used, we first checked that their corresponding requirements for them to be a valid choice were met.

\section{RESULTS}

The study included 102 right eyes that had SMILE. There were 58 men and 44 women with a mean age of $31.63 \pm 6.10$ years (range: 23 to 48 years). Table 1 shows the frequency distribution for preoperative astigmatism type and the median value of both spherical and cylindrical refractive errors within each sub- group. No statistically significant association emerged between astigmatism magnitude and type of astigmatism (chi-square $[4]=3.08, P=.56$ ).AQ3

The resulting postoperative astigmatism was 0.50 $\mathrm{D}$ or less for $93 \%$ of the eyes and $1.00 \mathrm{D}$ or less for $100 \%$ (Figure 1A). Target induced astigmatism (TIA) accounted for $95 \%$ of the surgically induced astigmatism (SIA) variation and a linear undercorrection was obtained with its increment, slope 0.92 (Figure 1B). The refractive angle of error was greater than $15^{\circ}$ in $4.9 \%$ of the eyes with no particular tendency for counterclockwise or clockwise errors (Figure 1C). However, the anterior cornea angle of error was greater than $15^{\circ}$ in $28.5 \%$ of the cases with a clear tendency of counterclockwise SIA from the TIA (Figure 1D). Furthermore, seven extreme outliers (angle of error $\geq 50^{\circ}$ ) were identified in the anterior cornea angle of error (Figure 1D). The mean preoperative corneal astigmatism of the anterior cornea was $0.66 \pm 0.44 \mathrm{D}$ for these 


\begin{tabular}{|c|c|c|c|c|}
\hline \multicolumn{5}{|c|}{$\begin{array}{c}\text { TABLE } 2 \\
\text { Prevalence of Postoperative Resultant Refractive Astigmatism Depending on } \\
\text { Preoperative Astigmatism Magnitude and Type }\end{array}$} \\
\hline Astigmatism & WTR & Oblique & ATR & $P^{\mathrm{a}} \mathrm{AQ3}$ \\
\hline \multicolumn{5}{|l|}{$0.50 \mathrm{D}$} \\
\hline Resultant cylinder, $\mathrm{n}(\%)$ & $3(8.8 \%)$ & $2(5.9 \%)$ & $0(0 \%)$ & $P=.10^{\mathrm{a}}$ \\
\hline No resultant cylinder, $\mathrm{n}(\%)$ & $16(47.1 \%)$ & $3(8.8 \%)$ & $10(29.4 \%)$ & - \\
\hline$A E\left(^{\circ}\right)$ & & & & chi-square(2) $=0.18, P=.92$ \\
\hline Arithmetic mean \pm SD & $-2.79 \pm 11.59$ & - & $-2.00 \pm 22.09$ & - \\
\hline Median (IQR) & $0(0)$ & $0(0)$ & - & \\
\hline ME (D) & & & & chi-square(2) $=0.11, P=.95$ \\
\hline Mean \pm SD & $0.03 \pm 0.15$ & $0.07 \pm 0.25$ & - & \\
\hline Median (IQR) & $0.02(0)$ & 0 (0.32) & - & \\
\hline $\mathrm{CA}$, geometric mean $\pm \mathrm{SD}$ & $0.98 \pm 1.36$ & $0.93 \pm 1.43$ & - & chi-square(2) $=1.79, P=.41$ \\
\hline \multicolumn{5}{|l|}{0.75 to $1.25 \mathrm{D}$} \\
\hline Resultant cylinder, n (\%) & $2(5.3 \%)$ & $0(0 \%)$ & $0(0 \%)$ & $P=1.00^{b}$ \\
\hline No resultant cylinder, n [\%] & $20(52.6 \%)$ & $7(18.4 \%)$ & $9(23.7 \%)$ & - \\
\hline$\left.A E l^{\circ}\right)$ & & & & - \\
\hline Arithmetic mean \pm SD & $0.52 \pm 4.87$ & - & - & - \\
\hline Median (IQR) & $0(0)$ & - & - & - \\
\hline \multicolumn{5}{|l|}{ ME (D) } \\
\hline Mean \pm SD & $0.03 \pm 0.1$ & - & - & - \\
\hline Median (IQR) & $0(0)$ & - & - & - \\
\hline $\mathrm{CA}$, geometric mean $\pm \mathrm{SD}$ & $0.97 \pm 1.09$ & - & - & - \\
\hline \multicolumn{5}{|l|}{$\geqslant 1.50 \mathrm{D}$} \\
\hline Resultant cylinder, n (\%) & $9(27.3 \%)$ & $1(3 \%)$ & $2(6.1 \%)$ & $P=.03^{b}$ \\
\hline No resultant cylinder, n (\%) & $6(18.2 \%)$ & $3(9.1 \%)$ & $12(36.4 \%)$ & \\
\hline$A E\left(^{\circ}\right)$ & & & & chi-square(2) $=1.72, P=.42$ \\
\hline Arithmetic mean \pm SD & $-1.57 \pm 3.99$ & $0.25 \pm 0.5$ & $1.00 \pm 3.74$ & \\
\hline Median (IQR) & $0(5)$ & $0(0.75)$ & $0(0)$ & \\
\hline$M E(D)$ & & & & chi-square $(2)=10.36, P=.006$ \\
\hline Mean \pm SD & $-0.26 \pm 0.33$ & $0.12 \pm 0.24$ & $0.08 \pm 0.20$ & \\
\hline Median (IQR) & $-0.3(0.48)$ & $0(0.36)$ & $0(0)$ & \\
\hline $\mathrm{CA}$, geometric mean $\pm \mathrm{SD}$ & $1.13 \pm 1.17$ & $0.93 \pm 1.13$ & $0.96 \pm 1.11$ & chi-square(2) $=5.3, P=.07$ \\
\hline \multicolumn{5}{|l|}{ Total } \\
\hline Resultant cylinder, $\mathrm{n}(\%)$ & $14(13.3 \%)$ & $3(2.9 \%)$ & $2(1.9 \%)$ & $P=.07^{\mathrm{a}}$ \\
\hline No resultant cylinder, n [\%] & $42(40 \%)$ & $13(12.4 \%)$ & $31(29.5 \%)$ & \\
\hline$A E\left({ }^{\circ}\right)$ & & & & chi-square(2) $=1.47, P=.48$ \\
\hline Arithmetic mean \pm SD & $-1.19 \pm 7.79$ & $-0.6 \pm 11.8$ & $0.42 \pm 2.446$ & \\
\hline Median (IQR) & $0(0)$ & $0(0)$ & $0(0)$ & \\
\hline ME (D) & & & & chi-square(2) $=3.0, P=.22$ \\
\hline Mean \pm SD & $-0.05 \pm 0.23$ & $0.05 \pm 0.18$ & $0.03 \pm 0.13$ & \\
\hline Median (IQR) & $0(0)$ & $0(0)$ & $0(0)$ & \\
\hline $\mathrm{CA}$, geometric mean $\pm \mathrm{SD}$ & $1.01 \pm 1.18$ & $0.96 \pm 1.25$ & $0.98 \pm 1.07$ & chi-square(2) $=0.83, P=.66$ \\
\hline 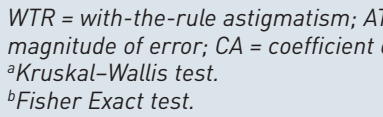 & $\begin{array}{l}\text { nst-the-rule astig } \\
\text { ment }\end{array}$ & liopters; $A E=a$ & $S D=$ standard de & $; \mid Q R=$ interquartile range; $M E=$ \\
\hline
\end{tabular}



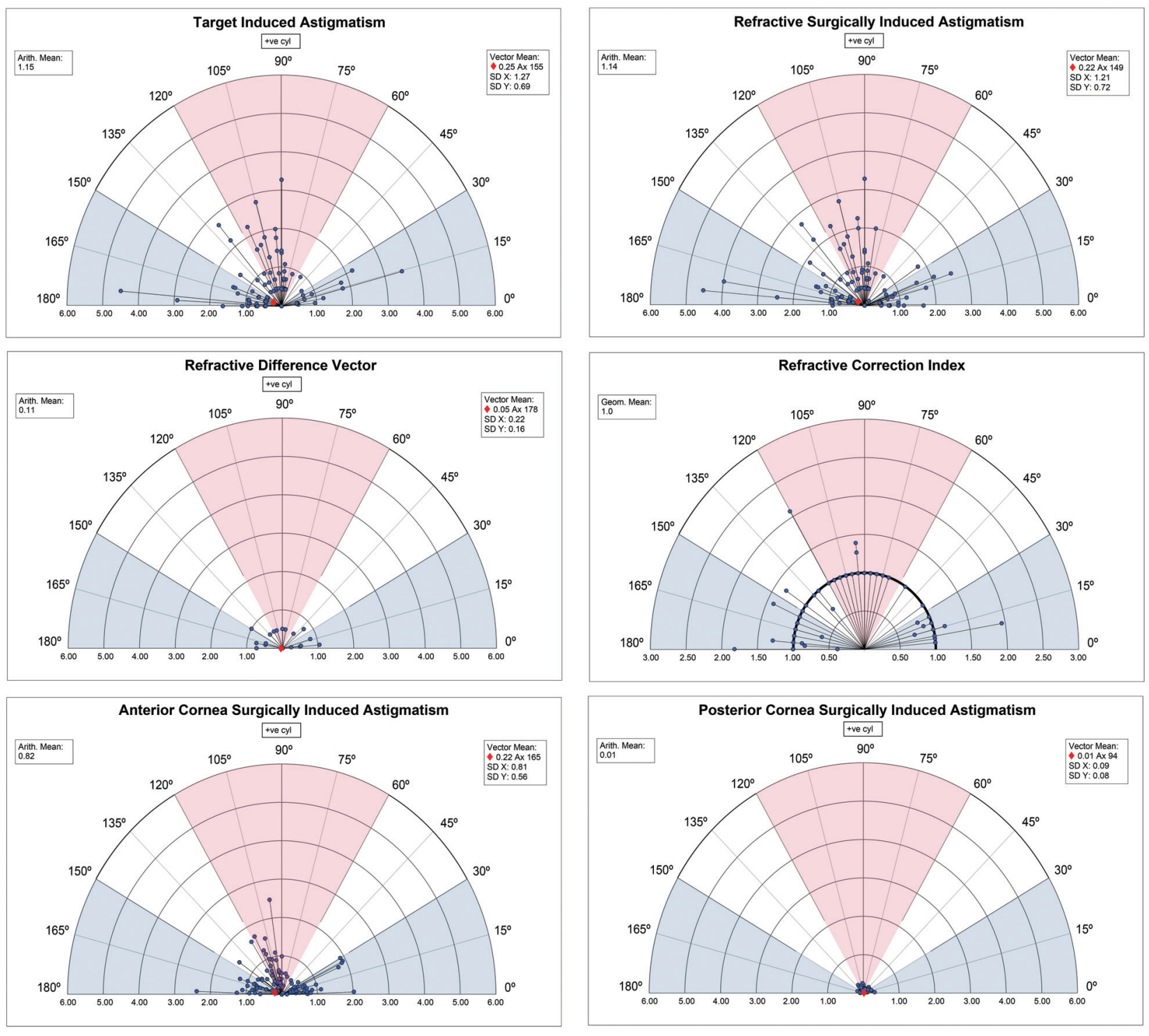

Figure 2. Standard single plots for reporting the target induced astigmatism vector (top left), the refractive surgically induced astigmatism vector (top right), the refractive difference vector (middle left) and the refractive correction index (middle right). Corneal surgically induced astigmatism is also represented for anterior cornea (bottom left) and posterior cornea (bottom right).

eyes versus $1.17 \pm 0.77 \mathrm{D}$ for the remaining 95 eyes $(z$ $=-1.79, P=.07)$.

The presence of resultant astigmatism was not linked with preoperative astigmatism type when the total patient population was considered, but for the group having astigmatism of $1.50 \mathrm{D}$ or greater, there was a significant association between the presence of resultant astigmatism and preoperative astigmatism type (Table 2). Particularly for the astigmatism of $1.50 \mathrm{D}$ or greater group, the magnitude of error was significantly more negative in the WTR group (median $=-0.30 \mathrm{D}$ ), resulting in a coefficient of adjustment equal to 1.13, which suggests a required overcorrection of $13 \%$ in this group.
However, the coefficient of adjustment was not significantly different among groups $(P=.07)$.

Figure 2 shows the standard plots for vector analysis. The arithmetic mean of the anterior corneal SIA was underestimated in comparison to the refractive mean SIA. However, the vector mean was equal in magnitude at $0.22 \mathrm{D}$. The posterior corneal astigmatism was not changed after surgery (Figure 2). The difference vector (DV) resulted in an arithmetic mean of $0.11 \mathrm{D}$ and vector mean of $0.05 @ 178^{\circ}$ for the total sample. The magnitude of error, angle of error, and coefficient of adjustment for each of the subgroups are shown in Table 2. 


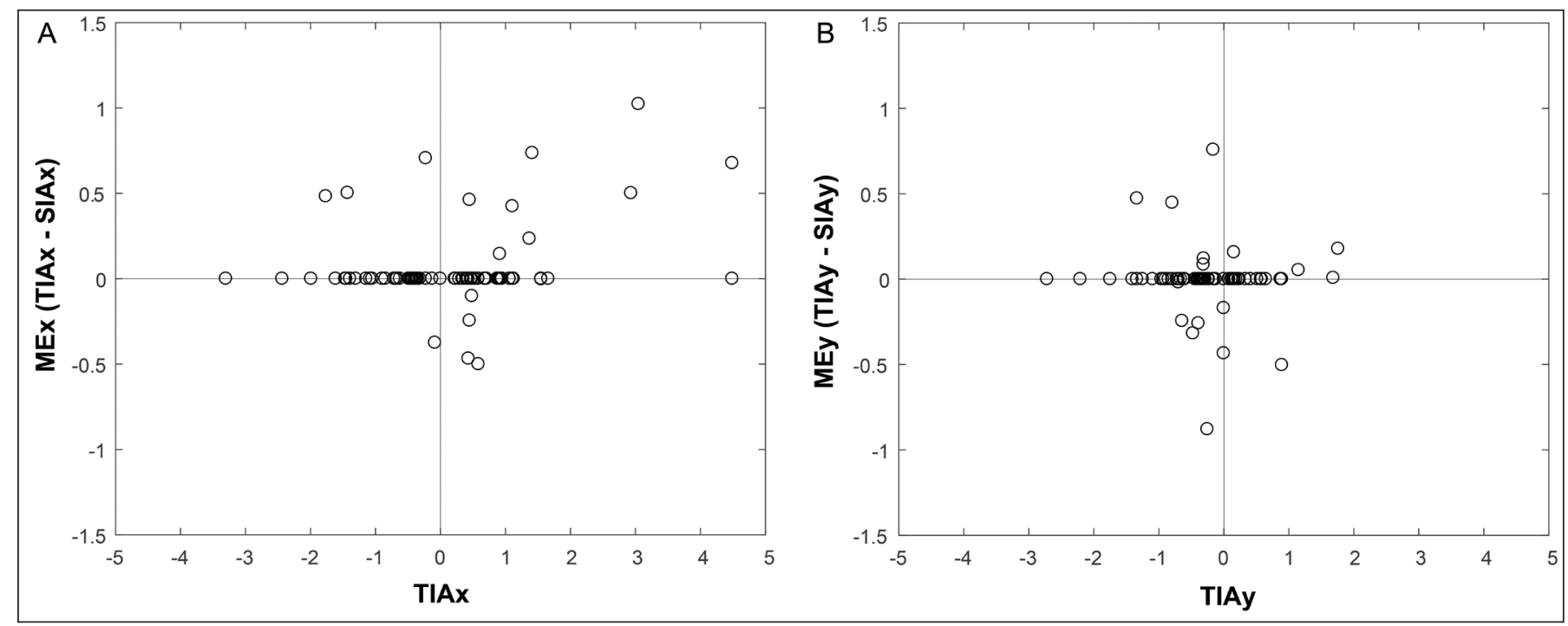

Figure 3. Orthogonal decomposition of the magnitude of error (ME) and the target induced astigmatism (TIA). (A) Positive values in the horizontal axis indicates preoperative with-the-rule astigmatism and negative preoperative against-the-rule astigmatism. Positive values in the vertical axis indicates astigmatism undercorrection and negative values overcorrection. (B) Oblique components for which positive values in the horizontal axis indicate $45^{\circ}$ and negative values indicate $135^{\circ}$.

For these variables, only the magnitude of error showed significant differences between astigmatism type groups in the $1.50 \mathrm{D}$ or greater group. Figure 3 shows a decomposition of orthogonal components of the magnitude of error and TIA, with a higher number of dots for positive TIAx and positive MEx, which indicates an undercorrection, especially for those cases for which TIAx was higher (higher WTR astigmatism).

\section{DISCUSSION}

Astigmatism correction with SMILE was evaluated as a function of the astigmatism level and type. We found that, in the context of SMILE refractive surgery, astigmatism correction was predictable for astigmatism levels of less than 1.50 D; in these cases, no correction seemed to be required by the surgeon. However, undercorrections were found for higher astigmatism cases of specific types.

Several studies have reported astigmatism outcomes in SMILE. Ivarsen and Hjortdal ${ }^{24}$ observed a significant undercorrection and increased errors when attempting higher degrees of astigmatic correction. In their low astigmatism group (mean attempted cylinder correction $1.04 \pm 0.57 \mathrm{D}$, range: 0.75 to $2.25 \mathrm{D}$ ), $77 \%$ of the eyes were within $\pm 0.50 \mathrm{D}$ and $95 \%$ were within $\pm 1.00 \mathrm{D}$ of the intended correction of spherical equivalent 3 months postoperatively. In their high astigmatism group (mean attempted cylinder correction: 2.61 \pm 0.76 , range: -2.50 to $-5.75 \mathrm{D}$ ), a total of $77 \%$ of the eyes were within $\pm 0.50 \mathrm{D}$ of the intended correction and $97 \%$ were within $\pm 1.00 \mathrm{D}$. The undercorrection was predicted by $13 \%$ per diopter of low myopic astig- matism and was $16 \%$ per diopter in high astigmatism. Pedersen et al. ${ }^{18}$ found an astigmatic undercorrection of approximately $11 \%$ (mean preoperative astigmatism: $1.81 \pm 1.00 \mathrm{D}$; range: 0.75 to $4.00 \mathrm{D}$ ). Our study is partly in agreement with the previous ones, but only in the case of WTR astigmatism $1.50 \mathrm{D}$ or greater, for which it is required a $13 \%$ of overcorrection according to the coefficient of adjustment.

On the other hand, Qian et al. ${ }^{25}$ and Zhang et al. ${ }^{26}$ found an overcorrection for low astigmatism levels ( $\leq$ $1.00 \mathrm{D}$ ). Our results are not in agreement with these two studies because we found good outcomes for astigmatism levels up to $1.25 \mathrm{D}$. For higher astigmatism cases, their results coincide with ours: undercorrection tends to increase with TIA.

Kobashi et al. ${ }^{27}$ also reported astigmatism undercorrection $(-0.33 \pm 0.45 \mathrm{D})$ in a patient sample whose astigmatism ranged from -1.00 to $-2.75 \mathrm{D}$. These outcomes were similar to those recently reported by Khalifa et al. ${ }^{28}$ (mean magnitude error $-0.20 \pm 0.35 \mathrm{D}$ ), although the latter included astigmatism levels up to $-3.25 \mathrm{D}$. Despite using non-conventional terminology, ${ }^{29}$ Kunert et al., ${ }^{30}$ found a slight astigmatic undercorrection (approximately $10 \%$ ) in a sample of 113 patients with myopic astigmatism (cylinder range: -6.00 to $-0.25 \mathrm{D}$ ).

As for our study, the undercorrections were $0.37 \pm$ $0.35 \mathrm{D}$ for the WTR, $0.13 \pm 0.25 \mathrm{D}$ for the oblique, and $0.11 \pm 0.29 \mathrm{D}$ for the ATR groups for astigmatism greater than $1.50 \mathrm{D}$. The other studies do not break down undercorrection values based on astigmatism type, but our results could be comparable to their average values. It is important to remark that, according our 
results, higher undercorrections would be obtained for higher WTR astigmatism cases.

Another study ${ }^{31}$ that evaluated the outcomes for myopic astigmatism (cylinder range: -0.50 to -2.75 D) for SMILE with the femtosecond lenticule extraction technique (SMILE by lifting the flap) also found an undercorrection $(-0.26 \pm 0.37 \mathrm{D})$. This is important because, although flap creation is supposed to induce astigmatism, ${ }^{32}$ the results of that study are in good agreement with our study and others where the SMILE technique was employed. Although we computed the mean and standard deviation in the $1.50 \mathrm{D}$ or greater group for comparison purposes, it is important to note that we consider that mean is a poor predictor of the central tendency in this case due to the non-normal distribution of the sample suggesting less undercorrection for WTR and more undercorrection for oblique and ATR astigmatism. In any case, according to what other authors have reported, an undercorrection is an advantage because it is much easier to correct a postoperative myopic undercorrection than a hyperopic shift. ${ }^{29}$ From a clinical point of view, undercorrection would be better than overcorrection because a change in the direction of the cylinder axis would probably be poorly accepted by patients. ${ }^{33}$

As we can see, most authors' conclusions are well aligned regarding astigmatism undercorrection in SMILE procedures. Most studies have concluded that one of the reasons behind astigmatism undercorrection could be cyclotorsion, because the SMILE procedures were performed without eye-tracker support. ${ }^{34}$

Furthermore, it is important to note that a clear tendency for counterclockwise SIA versus the TIA was appreciated in the anterior corneal surface but not in the refractive results. The maximum angle of error was above the $55^{\circ}$ obtained from refractive data (Figure 1C) in the anterior cornea (Figure 1D), which may be due to some outliers for obtaining the angle with Scheimpflug devices, especially in low corneal astigmatism. ${ }^{35}$ Important discrepancies in the angle of error for corneal and refractive results have been previously reported. ${ }^{22}$

These discrepancies between refractive and corneal results have been reported in other SMILE studies that agree with our study in the stable posterior corneal astigmatism after SMILE. ${ }^{36}$

Although our sample size was large (102 right eyes), one important limitation in this study is that most eyes (approximately $70 \%$ ) had astigmatism of less than $1.50 \mathrm{D}$. This is why we decided to stratify the sample into similarly distributed groups based on the sample's 33rd percentile. The subanalysis let us identify the specific scenarios in which preoperative astigma- tism type seems to influence the astigmatic outcome: those eyes having preoperative astigmatism of $1.50 \mathrm{D}$ or greater. This group included 29 eyes whose preoperative astigmatism was mainly WTR and ATR; only 4 eyes had oblique astigmatism. The unbalanced sample for astigmatism types in the $1.50 \mathrm{D}$ or greater group is another important limitation commonly found in astigmatism studies due to the higher prevalence of the WTR astigmatism. ${ }^{23,24}$ Future studies are required for high astigmatism and better group balance, especially in the case of oblique astigmatism, for which the prevalence is considerably lower. ${ }^{36}$

Treating astigmatism with the SMILE technique seems to yield predictable outcomes, but with a tendency toward slight undercorrection in high WTR astigmatism cases. Future studies comprising a larger sample size would be required to confirm our findings and to develop a valid nomogram including the preoperative astigmatism classification.

\section{AUTHOR CONTRIBUTIONS}

Study concept and design (RP-I, MR-V, NG, FP, JF); data collection (AM, NG); analysis and interpretation of data (MR-V, JM, FP, JF); writing the manuscript (MR-V, AM, JM, NG); critical revision of the manuscript (RP-I, FP, JF); supervision (RP-I, MR-V, AM, JM, NG, FP, JF)

\section{REFERENCES}

1. Sekundo W, Kunert KS, Blum M. Small incision corneal refractive surgery using the small incision lenticule extraction (SMILE) procedure for the correction of myopia and myopic astigmatism: results of a 6 month prospective study. Br J Ophthalmol. 2011;95:335-339.

2. Shah R, Shah S, Sengupta S. Results of small incision lenticule extraction: all-in-one femtosecond laser refractive surgery. $J$ Cataract Refract Surg. 2011;37:127-137.

3. Yuen LH, Chan WK, Koh J, Mehta JS, Tan DT. A 10-year prospective audit of LASIK outcomes for myopia in 37932 eyes at a single institution in Asia. Ophthalmology. 2010;117:12361244.

4. Vestergaard A, Ivarsen AR, Asp S, Hjortdal JO. Small-incision lenticule extraction for moderate to high myopia: predictability, safety, and patient satisfaction. J Cataract Refract Surg. 2012;38:2003-2010.

5. Ivarsen A, Asp S, Hjortdal J. Safety and complications of more than 1500 small-incision lenticule extraction procedures. Ophthalmology. 2014;121:822-828.

6. Fernández J, Valero A, Martínez J, Piñero DP, Rodríguez-Vallejo M. Short-term outcomes of small-incision lenticule extraction (SMILE) for low, medium, and high myopia. Eur J Ophthalmol. 2017;27:153-159.

7. Vestergaard A, Ivarsen A, Asp S, Hjortdal JO. Femtosecond (FS) laser vision correction procedure for moderate to high myopia: a prospective study of ReLEx® flex and comparison with a retrospective study of FS-laser in situ keratomileusis. Acta Ophthalmol. 2013;91:355-362.

8. Blum M, Kunert K, Schröder M, Sekundo W. Femtosecond 
lenticule extraction for the correction of myopia: preliminary 6-month results. Graefes Arch Clin Exp Ophthalmol. 2010;248:1019-1027.

9. Sekundo W, Kunert K, Russmann C, et al. First efficacy and safety study of femtosecond lenticule extraction for the correction of myopia: six-month results. J Cataract Refract Surg. 2008;34:1513-1520.

10. Alió del Barrio JL, Vargas V, Al-Shymali O, Alió JL. Small incision lenticule extraction (SMILE) in the correction of myopic astigmatism: outcomes and limitations: an update. Eye Vis. $2017 ; 4: 26$

11. Kanellopoulos AJ. Topography-guided LASIK versus small incision lenticule extraction (SMILE) for myopia and myopic astigmatism: a randomized, prospective, contralateral eye study. J Refract Surg. 2017;33:306-312.

12. Reinstein DZ, Carp GI, Archer TJ, Gobbe M. Outcomes of small incision lenticule extraction (SMILE) in low myopia. J Refract Surg. 2014;30:812-818. Erratum in: J Refract Surg. 2015;31:60.

13. Recchioni A, Hartwig A, Dermott J, et al. Early clinical outcomes after small incision lenticule extraction surgery (SMILE). Cont Lens Anterior Eye. 2018;41:132-135.

14. Liu YC, Rosman M, Mehta JS. Enhancement after small-incision lenticule extraction. incidence, risk factors, and outcomes. Ophthalmology. 2017;124:813-821.

15. Kim JR, Hwang HB, Mun SJ, Chung YT, Kim HS. Efficacy, predictability, and safety of small incision lenticule extraction: 6-months prospective cohort study. BMC Ophthalmol. 2014;14:117

16. Liang G, Chen X, Zha X, Zhang F. A nomogram to improve predictability of small-incision lenticule extraction surgery. Med Sci Monit. 2017;23:5168-5175.

17. Güell JL, Verdaguer P, Mateu-Figueras G, et al. SMILE procedures with four different cap thicknesses for the correction of myopia and myopic astigmatism. J Refract Surg. 2015;31:580585.

18. Pedersen IB, Ivarsen A, Hjortdal J. Changes in astigmatism, densitometry, and aberrations after SMILE for low to high myopic astigmatism: a 12-month prospective study. J Refract Surg. 2017;33:11-17.

19. Ivarsen A, Hjortdal J. With- or against-the-rule astigmatism, does it matter in SMILE surgery? Presented at the XXXV Congress of the European Society of Cataract and Refractive Surgery; October 7-11, 2017; Lisbon, Portugal.

20. Ganesh S, Brar S, Binesh Tyagi. Outcomes of astigmatism correction in with-the-rule and against-the-rule astigmatism in eyes having small-incision lenticule extraction for myopic astigmatism. Presented at the American Society of Cataract and Refractive Surgery Annual Meeting; April 13-17, 2018; Washington, DC.

21. Reinstein DZ, Archer TJ, Randleman JB. JRS standard for reporting astigmatism outcomes of refractive surgery. J Refract Surg. 2014;30:654-659.

22. Alpins N. Astigmatism analysis by the Alpins method. J Cata- ract Refract Surg. 2001;27:31-49.

23. Rodríguez-Vallejo M. Refractive Analysis v.1.0.0: a Matlab toolbox for the analysis of refractive results in anterior segment surgery. 2017. http://test-eye.com/index.php/en/refractiveanalysis Accessed March 24, 2018.

24. Ivarsen A, Hjortdal J. Correction of myopic astigmatism with small incision lenticule extraction. J Refract Surg. 2014;30:240247.

25. Qian Y, Huang J, Zhou X, Wang Y. Comparison of femtosecond laser small-incision lenticule extraction and laser-assisted subepithelial keratectomy to correct myopic astigmatism. J Cataract Refract Surg. 2015;41:2476-2486. doi:10.1016/j. jcrs.2015.05.043.

26. Zhang J, Wang Y, Wu W, Xu L, Li X, Dou R. Vector analysis of low to moderate astigmatism with small incision lenticule extraction (SMILE): results of a 1-year follow-up. BMC Ophthalmol. 2015;15:8.

27. Kobashi H, Kamiya K, Ali MA, Igarashi A, Elewa MEM, Shimizu K. Comparison of astigmatic correction after femtosecond lenticule extraction and small-incision lenticule extraction for myopic astigmatism. PLoS One. 2015;10:e0123408.

28. Khalifa MA, Ghoneim AM, Shaheen MS, Piñero DP. Vector analysis of astigmatic changes after small-incision lenticule extraction and wavefront-guided laser in situ keratomileusis. $J$ Cataract Refract Surg. 2017;43:819-824.

29. Alpins N. Vector analysis with the femtosecond laser. J Cataract Refract Surg. 2014;40:1246-1247.

30. Kunert KS, Russmann C, Blum M, Sluyterman VLG. Vector analysis of myopic astigmatism corrected by femtosecond refractive lenticule extraction. J Cataract Refract Surg. 2013:39:759-769.

31. Ali MA, Kobashi H, Kamiya K, et al. Comparison of astigmatic correction after femtosecond lenticule extraction and wavefront-guided LASIK for myopic astigmatism. J Refract Surg. 2014;30:806-811.

32. Katz T, Frings A, Richard G, Steinberg J, Druchkiv V, Linke SJ. Flap-induced astigmatism in eyes with sphere myopia correction: superior hinge using a rotating microkeratome versus nasal hinge using a linear microkeratome. J Cataract Refract Surg. 2015;41:1160-1167.

33. Felipe A, Artigas JM, Díez-Ajenjo A, García-Domene C, Alcocer P. Residual astigmatism produced by toric intraocular lens rotation. J Cataract Refract Surg. 2011;37:1895-1901.

34. Chang J. Cyclotorsion during laser in situ keratomileusis. J Cataract Refract Surg. 2008;34:1720-1726.

35. Lee BW, Galor A, Feuer WJ, et al. Agreement between Pentacam and IOLMaster in patients undergoing toric IOL implantation. J Refract Surg. 2013;29:114-120.

36. Kamiya K, Shimizu K, Yamagishi M, Igarashi A, Kobashi H. Anterior and posterior corneal astigmatism after refractive lenticule extraction for myopic astigmatism. J Ophthalmol. 2015;2015:1-6 


\section{AUTHOR QUERIES}

$\mathbf{A Q} \mathbf{1}_{1=}$ If these were authors, please indicate which ones.

$\mathbf{A Q}=$ Please provide the name and location of the manufacturer.

Tables Please indicate what the chi square (4) and chi square (2) mean. Generally only the P value is listed, so is the chi square value necessary? 